Correspondence

\title{
Ecological integrity assessment, ecosystem-based approach, and integrative methodologies: Are these concepts equivalent?
}

Recently, Borja et al. (2008b) published an overview of integrative tools and methods for assessing ecological integrity in estuarine and coastal systems worldwide. This contribution collates the presentations and ideas debated among the attendees of the special session on 'Integrative tools and methods in assessing ecological integrity in estuarine and coastal systems', organised by two of the co-authors at the 'EcoSummit 2007 - Ecological Complexity and Sustainability' conference in Beijing (China), in May 2007.

Chapman (2009) commented that he was surprised by the omission of several well-established, integrative techniques, such as Sediment Quality Triad (SQT), Weight-of-Evidence (WOE), and Ecological Risk Assessment (ERA).

Is this really an omission, or simply, are we talking about different issues? When discussing integrative tools and methods in assessing ecological integrity, we were aware of the different meanings of the terms 'integrative methodologies' and 'ecological integrity'. Indeed, the lack of a coherent terminology to differentiate the various assessment types and the diverse nature of aquatic environmental assessments is currently being discussed (Morishita, 2008; Foden et al., 2008).

Marine and estuarine environments are facing increasing and significant impacts, which include physical and chemical transformation, habitat destruction and changes in biodiversity (Halpern et al., 2007, 2008a,b). Causes include land reclamation, dredging, pollution (sediment discharges, hazardous substances, litter, oilspills, eutrophication, etc.), unsustainable exploitation of marine resources (sand extraction, oil and gas exploitation, fishing, etc.), unmanaged tourism, introduction of alien species and climate change (see Halpern et al. (2007)).

To manage these pressures and impacts on marine environments, recent legislative instruments approved worldwide address the need to assess their ecological status. The concept of environmental or ecological status takes into account the structure, function and processes of marine ecosystems bringing together natural physical, chemical, physiographic, geographic and climatic factors, and integrates these conditions with the anthropogenic impacts and human activities in the area concerned.

As commented in Borja et al. (2008b), the above concept defines quality in an integrative way, by using several biological parameters (from phytoplankton to mammals) together with physico-chemical and pollution elements. In a recent paper, Rogers et al. (2007) review the selection of the ecosystem components, adding to the abovementioned structural components other ecosystem attributes such as food web dynamics, species diversity, and the distribution of life histories, that are not direct biological properties but functions of the entire ecosystem. They are important because they provide information about the func- tioning and status of the ecosystem, and have been widely perceived as additional and potentially useful indicators of environmental status. This approach is intended to allow an assessment of the ecological status at the ecosystem level ('ecosystem-based approach' or 'holistic approach' methodologies, more effectively than can be done at a species or chemical level (i.e. quality objectives).

'Ecosystem-based management' emphasizes four common principles, namely that effective management must (Boesch, 2006; Elliott et al., 2006): (1) be integrated among components of the ecosystem and resource uses and users; (2) lead to sustainable outcomes; (3) take precaution in avoiding deleterious actions; and (4) be adaptive in seeking more effective approaches based on experience.

There are many different forms of the ecosystem-based approach for management, one of them being the 'integrated ecosystem approach' (Morishita, 2008). Integration, as used by the management and policy community, generally implies collective consideration of the uses of products and services provided by the coastal environment to determine an 'optimal mix' (Boesch, 2006). Good definitions of what is called 'integrated management' can be found in O'Boyle and Jamieson (2006).

From these scientists' point of view, an ecosystem-based approach should explicitly account for the interconnections within the ecosystem, recognizing the importance of interactions among many target species or key services and other non-target species; acknowledge interconnections among ecosystems, such as air, land and sea; and integrate ecological, social, economic, and institutional perspectives, recognizing their strong interdependences (Boesch, 2006).

However, are all integrative tools currently available able to respond to these requirements of the ecosystem-based approach? Following Chapman's letter, this is the primary objective of the SQT, considering it not just chemistry or laboratory studies or resident community studies, but rather all of these together, in a WOE assessment. Although, the SQT can be considered an integrative tool (because it incorporates several compartments of the ecosystem), and it is very well-established internationally, we disagree that SQT and the others are 'tools in assessing ecological integrity' or methods focusing on the 'ecosystem-based approach'. In general, the tools mentioned by Chapman are focused on assessing pollution (and, of course, we use them in some of our research). Based on some of the current legislation (European Water Framework Directive (WFD), EU Marine Strategy Directive, Oceans Act, etc.), we are of the opinion that managers and politicians are seeking tools to assess the quality at the ecosystem level, whilst some of the current spectrum of tools on offer looks only at ecotoxicological effects, normally at individual or population levels 
(sometimes at the community level), but not at the ecosystem level.

From our perspective SQT, WOE and ERA (even Toxicity Identification Evaluation (TIE)), not mentioned by Chapman), are useful tools for agency staff and consultants operating in structured contexts for setting and auditing performance criteria for specific aspects of environmental management. However, we consider that they do not address the multiple scale issues of ecological integrity assessment (ecosystem-based approach) that our paper addressed. These methods have as a main aim an assessment of the risks associated with potential adverse factors (normally pollutants, and not other pressures, such as hydromorphological, fishing, etc.), and its transfer to other compartments of the system. As a rule, they are looking for relationships between compartments and the pollutants responsible for detected alterations, as a means to support management decisions.

We believe that whilst SQT, WOE, etc., evaluate risk and state of a particular system (sensu the DPSIR (Drivers-Pressures-State-Impacts-Response) approach), the 'ecological integrity' and 'ecosystem-based approach' refer to the status of the whole ecosystem.

The current uncertainty concerning the definition of the ecosystem-based approach is creating several problems in management (Morishita, 2008), one of them being this ambiguity highlighted by Chapman (2009). Of course, the methodologies mentioned by Chapman (2009) can assist the investigators in further developments of the ecosystem-based approach, and, in fact, some of the co-authors are investigating its use within the WFD (see Borja et al. (2008a)). However, we continue to be convinced that very few methodologies are currently available for integrating physico-chemical and biological (multiple) elements in assessing ecological status on the basis of an ecosystem-based approach, as stated also by Morishita (2008).

\section{References}

Boesch, D.F., 2006. Scientific requirements for ecosystem-based management in the restoration of Chesapeake Bay and Coastal Louisiana. Ecological Engineering 26, 6-26.

Borja, A., Tueros, I., Belzunce, M.J., Galparsoro, I., Garmendia, J.M., Revilla, M., Solaun, O., Valencia, V., 2008a. Investigative monitoring within the European Water Framework Directive: a coastal blast furnace slag disposal, as an example. Journal of Environmental Monitoring 10, 453-462.

Borja, A., Bricker, S.B., Dauer, D.M., Demetriades, N.T., Ferreira, J.G., Forbes, A.T., Hutchings, P., Jia, X., Kenchington, R., Marques, J.C., Zhu, C., 2008b. Overview of integrative tools and methods in assessing ecological integrity in estuarine and coastal systems worldwide. Marine Pollution Bulletin 56, 1519-1537.

Chapman, P.M., 2009. Borja et al.'s (2008) “Overview of integrative tools and methods .. worldwide" is curiously deficient. Marine Pollution Bulletin 59 (3), 456

Elliott, M., Burdon, D., Hemingway, K.L., 2006. Marine Ecosystem Structure, Functioning, Health and Management and Potential Approaches to Marine Ecosystem Recovery: a Synthesis of Current Understanding. Institute of Estuarine and Coastal Studies, University of Hull, Report to CCW, Reference No: YBB092-F-2006, p. 122.

Foden, J., Rogers, S.I., Jones, A.P., 2008. A critical review of approaches to aquatic environmental assessment. Marine Pollution Bulletin 56, 1825-1833.

Halpern, B.S., Selkoe, K.A., Micheli, F., Kappel, C.V., 2007. Evaluating and ranking the vulnerability of global marine ecosystems to anthropogenic threats. Conservation Biology 21, 1301-1315.

Halpern, B.S., Walbridge, S., Selkoe, K.A., Kappel, C.V., Micheli, F., D’Agrosa, C., Bruno, J.F., Casey, K.S., Ebert, C., Fox, H.E., Fujita, R., Heinemann, D., Lenihan, H.S., Madin, E.M.P., Perry, M.T., Selig, E.R., Spalding, M. Steneck, R., Watson, R. 2008a. A global map of human impact on marine ecosystems. Science 319, 948952.

Halpern, B.S., McLeod, K.L., Rosenberg, A.A., Crowder, L.B., 2008b. Managing for cumulative impacts in ecosystem-based management through ocean zoning. Ocean and Coastal Management 51, 203-211.

Morishita, J., 2008. What is the ecosystem approach for fisheries management. Marine Policy 32, 19-26.

O'Boyle, R., Jamieson, G., 2006. Observations on the implementation of ecosystembased management: Experiences on Canada's east and west coasts. Fisheries Research 79, 1-12.

Rogers, S.I., Tasker, M.L., Earll, R., Gubbay, S., 2007. Ecosystem objectives to support the UK vision for the marine environment. Marine Pollution Bulletin 54, 128144.
Angel Borja

AZTI-Tecnalia,

Marine Research Division,

Herrera Kaia, Portualdea $s / n$, 20110 Pasaia, Spain

E-mail address: aborja@pas.azti.es

Suzanne B. Bricker

NOAA - National Ocean Service,

National Centers for Coastal Ocean Science, 1305 East West Highway, Silver Spring, MD 20910,

USA

Daniel M. Dauer Department of Biological Sciences, Old Dominion University, Norfolk, VA 23529,

USA

Nicolette T. Demetriades Marine and Estuarine Research, P.O. Box 417, Hyper by the Sea, 4053 , South Africa

João G. Ferreira IMAR - Institute of Marine Research, Centre for Ocean and Environment, FCT-UNL, Portugal

Anthony T. Forbes Marine and Estuarine Research, P.O. Box 417, Hyper by the Sea, 4053, South Africa

Pat Hutchings Marine Invertebrates, Australian Museum, Sydney, NSW 2010,

Australia

Xiaoping Jia South China Sea Fisheries Research Institute, CAFS, PR China

Richard Kenchington Australian National Centre for Ocean Resources and Security, University of Wollongong, NSW 2522,

Australia

João Carlos Marques IMAR - Institute of Marine Research, University of Coimbra,

Portugal

Changbo Zhu

South China Sea Fisheries Research Institute CAFS, PR China 